\title{
Adsorption of Titanium Halides on Nitride and Oxide Surfaces during Atomic Layer Deposition: A DFT Study
}

\author{
Jeongwoo Park ${ }^{1}$, Neung Kyung Yu ${ }^{1}$, Donghak Jang ${ }^{2}$, Eunae Jung ${ }^{2}$, Hyunsik Noh ${ }^{2}$, \\ Jiwon Moon ${ }^{2}$, Deoksin Kil ${ }^{2}$ and Bonggeun Shong ${ }^{1, * \mathbb{D}}$ \\ 1 Department of Chemical Engineering, Hongik University, 94 Wausan-ro, Sangsu-dong, Mapo-gu, \\ Seoul 04066, Korea; pjw2114@naver.com (J.P.); ingk1@naver.com (N.K.Y.) \\ 2 R\&D Division, SK hynix Inc., 2091 Gyeongchung-daero, Bubal-eup, Icheon-si, Gyeonggi-do 17336, Korea; \\ donghak.jang@sk.com (D.J.); eunae1.jung@sk.com (E.J.); hyunsik.noh@sk.com (H.N.); \\ jiwon.moon@sk.com (J.M.); deoksin.kil@sk.com (D.K.) \\ * Correspondence: bshong@hongik.ac.kr
}

Received: 9 June 2020; Accepted: 20 July 2020; Published: 23 July 2020

\begin{abstract}
Various processes based on atomic layer deposition (ALD) have been reported for growing Ti-based thin films such as $\mathrm{TiN}$ and $\mathrm{TiO}_{2}$. To improve the uniformity and conformity of thin films grown via ALD, fundamental understanding of the precursor-substrate surface reactions is required. Herein, we present a density functional theory (DFT) study of the initial nucleation process of some titanium halide precursors $\left(\mathrm{TiCl}_{4}, \mathrm{TiBr}_{4}\right.$, and $\left.\mathrm{TiI}_{4}\right)$ on $\mathrm{Si}$ surfaces having $-\mathrm{OH}$ or $-\mathrm{NH}_{2}$ functional groups. We consider the most favorable adsorption site in the reaction between the precursor and functional group of the surface, based on the thermodynamics and kinetics of the reaction. Sequential dissociation reaction mechanisms of halide ligands were systematically investigated. The exothermicity of the dissociative adsorption was found to be in the order of: $\mathrm{TiI}_{4}>\mathrm{TiBr}_{4}>\mathrm{TiCl}_{4}$. In addition, the precursors were observed to be more exothermic and show higher reaction rate constant when adsorbed on the-OH-terminated surface than on the $-\mathrm{NH}_{2}$-terminated surface. These observations reveal the selectivity of deposition by surface functional groups.
\end{abstract}

Keywords: adsorption mechanism; precursor chemistry; $\mathrm{TiO} x$; $\mathrm{TiN} x$; selective deposition

\section{Introduction}

Considerable research efforts have been channeled on improving the integration density of semiconductors via device scaling, and attention has been focused on developing materials to overcome various problems induced by the miniaturization of metal-oxide-semiconductor field-effect transistors (MOSFETs) [1]. For a long time, novel electrode materials have been researched to minimize the deterioration of device characteristics, such as depletion effects, caused by conventional doped polycrystalline silicon gates in metal-oxide semiconductors. Alternative materials for these polycrystalline silicon gates are required to exhibit moderate work function (4-5 eV), low electrical resistivity, and metallic properties. Titanium nitride (TiN), one of the metals satisfying these conditions, has a high melting point, thermal stability, and conductivity, and, as such, it adequately satisfies the performance requirement of a metal electrode in a MOSFET [2]. TiN thin films exhibiting such excellent material properties are widely used to prevent device degradation caused by high-temperature heat treatment in a $\mathrm{Cu}$ interconnection of the ultra-large-scale integration structure as a potential diffusion barrier [3,4]. On the other hand, a similar Ti-based material, $\mathrm{TiO}_{2}$, possesses properties different from those of TiN, including low carrier mobility and photocatalytic effect. $\mathrm{TiO}_{2}$ exists in several different crystalline phases—rutile, anatase, and brookite—each having a different bandgap 
energy (3, 3.2, and $3.1 \mathrm{eV}$, respectively) [5] and exhibiting different photoactive effects. In addition, non-stoichiometric properties, such as oxygen vacancies on the $\mathrm{TiO}_{2}$ surface, influence the electrical properties of semiconductor materials. This has attracted considerable research $[5,6]$.

Various techniques, such as sol-gel method [7,8], liquid phase method [9], chemical vapor deposition (CVD) [10,11], and RF magnetron sputtering [12], have been employed to grow high-quality Ti-based thin films. Among these, atomic layer deposition (ALD) possess unique advantage of conformal and uniform deposition via controlled surface reactions [13]. The ALD technique is especially employed when excellent film quality and precise thickness control are required, such as in metal gates, oxide films, and capacitors. There are several precursors used for growing pure titanium, such as $\mathrm{TiCl}_{4}$ [14-16], $\mathrm{Ti}(\mathrm{OMe})_{4}$ [17], $\mathrm{Ti}\left(\mathrm{NMe}_{2}\right)_{4}$ [18,19], and $\mathrm{Ti}(\mathrm{OiPr})_{4}$ (TTIP) [20,21]. Among them, $\mathrm{TiCl}_{4}$ exhibits relatively simple vapor deposition chemistry and excellent thermal stability, and, hence, it does not readily decompose in the gas phase. In addition, $\mathrm{TiCl}_{4}$ has a higher vapor pressure than other halides, including fluorides, bromides, and iodides and hence exists in a liquid phase at room temperature [22]. It is, therefore, a good precursor candidate for the CVD/ALD technique [23]. As an example, TiN thin films have been successfully deposited via ALD using $\mathrm{TiCl}_{4}$ and pure $\mathrm{NH}_{3}$ as the precursors. Several studies have also reported superior qualities of thin films, such as low electrical resistance and good crystallinity, via ALD [24,25]. However, halide contamination commonly found in thin films affects the device reliability, and the hydrogen halide generated as a byproduct may damage not only the underlying layer but also the ALD reactor and its piping system [26,27]. Although many studies are ongoing to resolve these problems (e.g., plasma-enhanced ALD [28]), the titanium halide series still holds commercialization potential. On the other hand, while the use of $\mathrm{TiCl}_{4}$ as an ALD precursor has been extensively studied, less consideration has been given to the deposition studies of other halide precursors, especially regarding comparison between them. The other titanium halides $\left(\mathrm{TiF}_{4}, \mathrm{TiBr}_{4}\right.$, and $\left.\mathrm{TiI}_{4}\right)$ have been less utilized than $\mathrm{TiCl}_{4}$ possibly because of the following reasons. $\mathrm{TiF}_{4}$ would produce highly toxic $\mathrm{HF}$ as byproduct, and is more often used as a precursor for fluorine than titanium $[29,30]$. On the other hand, $\mathrm{TiBr}_{4}$ and $\mathrm{TiI}_{4}$ have with vapor pressure [22] and often require heating for evaporation.

In this study, the initial adsorption reactions of titanium halide precursors, including $\mathrm{TiCl}_{4}, \mathrm{TiBr}_{4}$, and $\mathrm{TiI}_{4}$, are analyzed on $\mathrm{Si}$ surfaces bearing $-\mathrm{OH}$ and $-\mathrm{NH}_{2}$ functional groups. To analyze this initial nucleation mechanism, quantum simulations based on density functional theory (DFT) were performed, and the calculation results obtained were evaluated based on thermodynamic and kinetic perspectives. Current study may contribute to further understanding on the experimental behaviors of these titanium halide molecules on the surfaces.

\section{Computational Methods}

A Si cluster $\left(\mathrm{Si}_{15} \mathrm{H}_{16}\right)$ with four $-\mathrm{OH}-$ and $-\mathrm{NH}_{2}$-terminating groups, as shown in Figure 1, was employed to model the surface. The cluster models are local structures that represent the characteristics of $\mathrm{Si}(001)$, and the dangling bonds present on the truncating plane were deactivated by passivation with hydrogen atoms, thereby minimizing the errors that could occur during the electronic structure calculations [31]. All calculations were performed using Gaussian 16 package [32]. The atomic mechanism for the thermodynamic and kinetic analysis was investigated using B97-D3 functional including empirical dispersion correction [33]. To obtain the ground-state geometry in all calculations, LANL2DZ effective core potential was used for the I atom, and def2-tzvp basis set was used for the other atoms [34].

The thermodynamic properties covered in this study include thermal energy $(E)$, enthalpy $(H)$, entropy $(S)$, and Gibbs free energy $(G)$. Their values were obtained by calculating the vibrational frequency according to the desired temperature, based on the optimized structure in the gas phase [35,36]. The rotational and translational degrees of freedom appearing in the entropy term were excluded from the calculations involving surface reactions on Si clusters [37,38]. In other words, only the vibrational 
degree of freedom was considered, and thus, the Gibbs free energy $(G)$ was derived using the following thermodynamic Equation:

$$
G=H-T S
$$

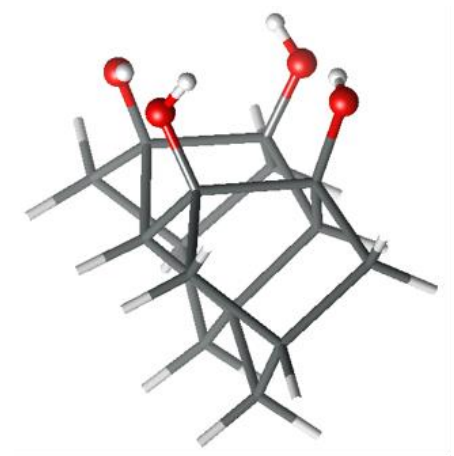

(a)

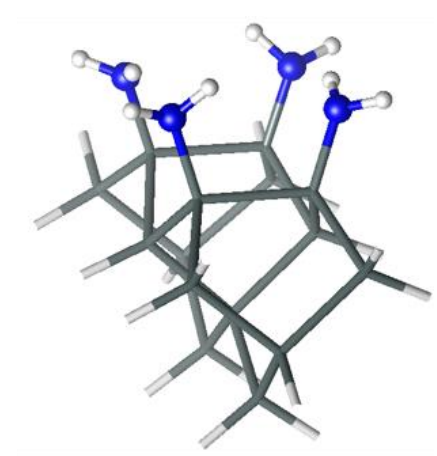

(b)

Figure 1. Cluster models: (a) $-\mathrm{OH}$ functionalized Si cluster; and (b) $-\mathrm{NH}_{2}$ functionalized Si cluster $($ red $=\mathrm{O}$, blue $=\mathrm{N}$, white $=\mathrm{H}$, green $=\mathrm{Si})$.

The reaction kinetics between the surface and precursors were evaluated using the transition state theory. After determining the magnitude of the energy barrier observed in the transition state, the reaction rate constant $(k)$ was obtained from the Eyring Equation [39]:

$$
k=\frac{\kappa k_{B} T}{h} \mathrm{e}^{\frac{\Delta S^{\ddagger}}{R}} \mathrm{e}^{-\frac{\Delta H^{\ddagger}}{R T}}
$$

where $k_{B}$ is the Boltzmann constant, $\kappa$ is the transmission coefficient, $h$ is the Planck constant, $T$ is the temperature, $R$ is the ideal gas constant, and $\Delta S^{\ddagger}$ and $\Delta H^{\ddagger}$ are the changes in entropy and enthalpy between the transition state and reactants, respectively.

The bond dissociation energy (BDE) of the $\mathrm{TiX}_{4}$ precursors was calculated through the following equation:

$$
\mathrm{BDE}=E_{\mathrm{X}}+E_{\mathrm{TiX}_{3}}-E_{\mathrm{Tix}_{4}}
$$

where $E_{\mathrm{X}}, E_{\mathrm{TiX}}$, and $E_{\mathrm{TiX}_{4}}$ are electronic energy of each chemical species involved in homolytic Ti-X bond dissociation.

\section{Results and Discussion}

To investigate the initial nucleation of ALD of Ti-based thin films, the reactions between the titanium halide precursor and the Si surface with different functional groups were considered. Several cases when $\mathrm{TiCl}_{4}, \mathrm{TiBr}_{4}$, and $\mathrm{TiI}_{4}$ precursors were introduced over two Si clusters with four $-\mathrm{OH}$ and $-\mathrm{NH}_{2}$ functional groups. To simulate the first half-reaction of $\mathrm{TiN}$ and $\mathrm{TiO}_{2} \mathrm{ALD}$, we adopted the mechanism reported in the existing literature that studied the surface reaction between the titanium halide precursor and the Si surface [40]: the hydrogen of the surface functional group reacts with the halogen ligand of the precursor, to form hydrogen halide (HX) as a byproduct, as well as $\mathrm{Si}-\mathrm{O}-\mathrm{TiX}_{3}{ }^{*}$ or $\mathrm{Si}-\mathrm{NH}-\mathrm{TiX}_{3}{ }^{*}$, depending on the functionalized surface (Figure 2). In other words, a proton-transfer, Brønsted-Lowry acid-base reaction between the surface functionalities and the halide ligands occur, so that Ti undergo ligand-exchange and form direct bond with the surface.

Figure 3 shows the optimized geometries obtained by dividing the reaction process into five steps until the first ligand of the $\mathrm{TiCl}_{4}$ precursor is removed. In addition, PES (potential energy surface) was represented at different temperatures along with the Gibbs free energies at each stage. $\mathrm{As}^{\mathrm{TiCl}} 4$ approach the Si surface at room temperature, a physisorbed state can form spontaneously with a slight exothermicity. At this point, an interaction occurred between the $d$-orbital of Ti and the lone pair 
electrons of the surface functional group element $(\mathrm{O}$ or $\mathrm{N})$, which affected the Ti-Cl bonding. This was confirmed by the change in the bond length of the $\mathrm{TiCl}_{4}$ precursor, and the $\mathrm{Ti}-\mathrm{Cl}$ bond length increased from 2.18 to $2.27 \AA$ in the adsorbed state. Subsequently, a transition state appeared during the process of forming a new bond between the hydrogen and chlorine atoms, and had a distorted triangular-pyramid shape, as shown in Figure 3, Structure 3. At room temperature, the energy barriers for $\mathrm{Cl}$ ligand dissociation of the adsorbed $\mathrm{TiCl}_{4}$ were 20 and $67 \mathrm{~kJ} / \mathrm{mol}$ for $-\mathrm{OH}-$ and $-\mathrm{NH}_{2}$-terminated surfaces, respectively. Therefore, the reaction rate was faster at the $-\mathrm{OH}$-terminated surfaces. In addition, the $\mathrm{Si}-\mathrm{NH}-\mathrm{TiCl}_{3}{ }^{*}$ structure was thermodynamically endothermic with a molar energy of $19 \mathrm{~kJ} / \mathrm{mol}$, whereas $\mathrm{Si}-\mathrm{O}-\mathrm{TiCl}_{3}{ }^{*}$ was exothermic with an energy of $-36 \mathrm{~kJ} / \mathrm{mol}$. Considered thermodynamically and kinetically, both the lower activation energy and greater exothermicity of the-OH-functionalized surface showed higher reactivity with the $\mathrm{TiCl}_{4}$ precursor compared to the $-\mathrm{NH}_{2}$-functionalized surface. Previous DFT calculations and experimental studies using tetrakis(dimethylamido)titanium precursors have revealed that the initial nucleation was more favorable at the -OH-terminated surfaces than the $-\mathrm{NH}_{2}$ surfaces [41,42], which is consistent with the results obtained here.

(a)<smiles>[Y]C[C@H]([AsH2])O[Si](C)(C)C</smiles>

(b)

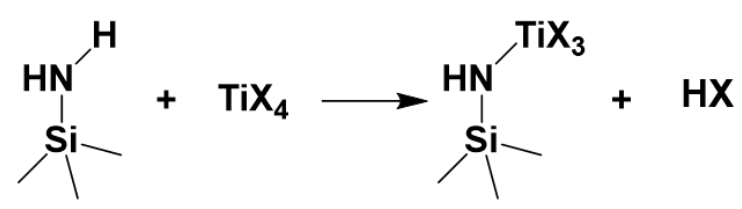

Figure 2. Suggested adsorption mechanism of $\mathrm{TiX}_{4}$ on: (a) $-\mathrm{OH}$ functionalized Si cluster; and (b) $-\mathrm{NH}_{2}$ functionalized Si cluster.

Besides these PESs at room temperature, we further investigated the effect of reaction temperature on the change in Gibbs free energy. As shown in Figure 3, the reaction free energy tended to increase with the reaction temperature for the first $\mathrm{HCl}$ removal process. The molecular adsorbed state of the precursor exhibited a negative Gibbs free energy up to room temperature in both surface models. However, at or above $500 \mathrm{~K}$, the Gibbs free energy became positive, indicating that the adsorbed complex was less stable than it was before the adsorption. Interpolating the free energy of molecular adsorption at each temperature, we find that the temperatures at which the change in Gibbs free energy are equal to zero are 346.5 and $424.5 \mathrm{~K}$ on $-\mathrm{OH}$ and $-\mathrm{NH}_{2}$ terminated surfaces, respectively. These are the temperatures at which molecular adsorption may occur reversibly for the respective surfaces, such that the molecular adsorption of the precursor may be energetically nonspontaneous above these temperatures. Therefore, a direct, non-physisorption-mediated reaction path might prevail at higher temperatures, while molecular physisorption can be expected to precede chemisorption at lower temperatures. Experimentally, relatively wide ALD temperature windows of ca. $100-500{ }^{\circ} \mathrm{C}$ (373-773 K) for $\mathrm{TiO}_{2}$, and ca. $350-500^{\circ} \mathrm{C}(623-773 \mathrm{~K})$ for TiN were reported for thermal ALD processes utilizing $\mathrm{TiCl}_{4}$ with $\mathrm{H}_{2} \mathrm{O}$ and $\mathrm{NH}_{3}$, respectively [43,44], which are mostly above the temperatures at which molecular adsorption of the precursors are nonspontaneous. More clear correlation with the ALD temperatures would require consideration on the reactivities of the secondary reactants on the surfaces [45]. 
(a)
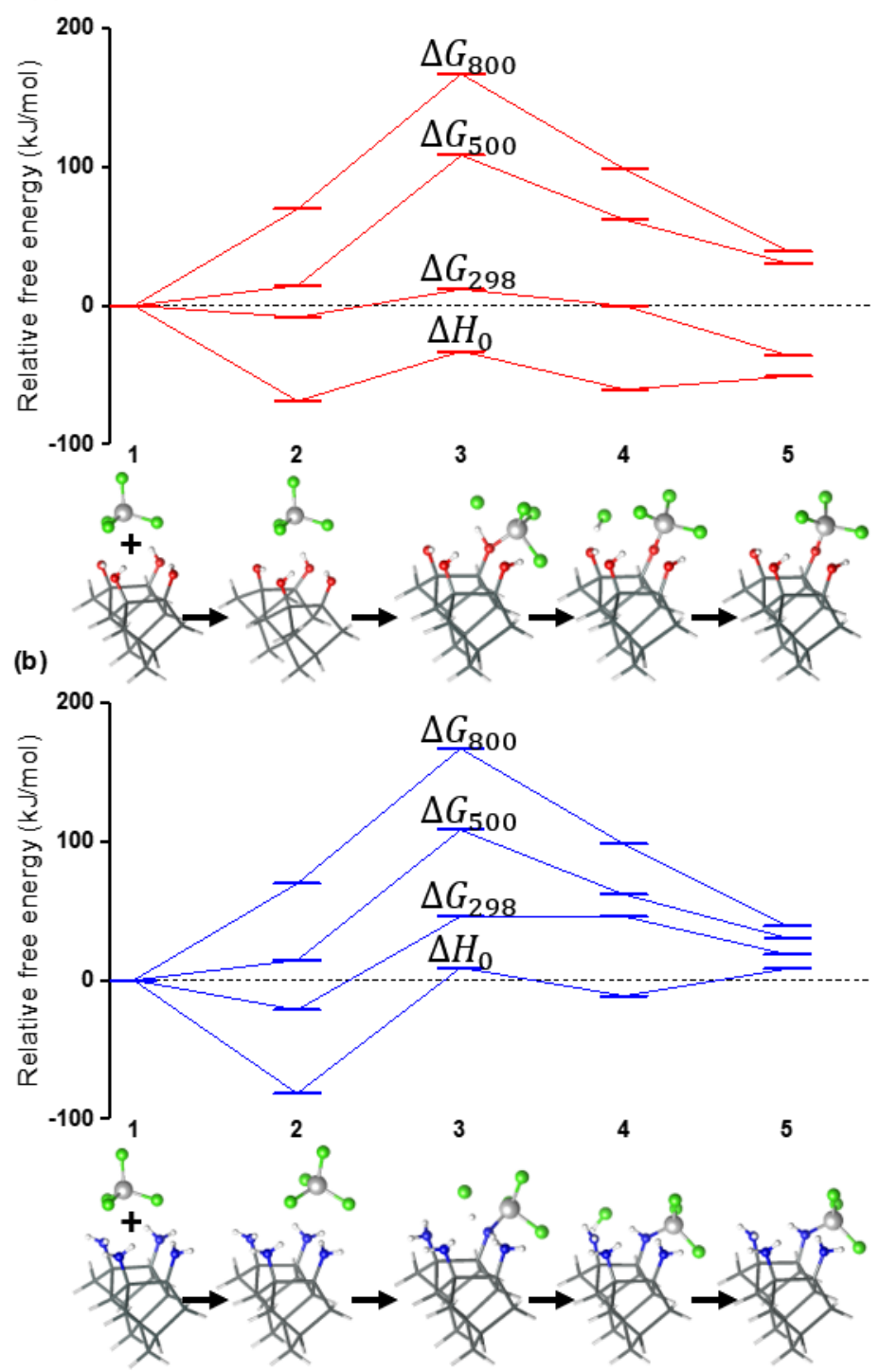

Figure 3. Potential energy surface $\left(\Delta H_{0}\right)$ and Gibbs free energy surfaces at $298 \mathrm{~K}\left(\Delta G_{298}\right), 500 \mathrm{~K}\left(\Delta G_{500}\right)$, $800 \mathrm{~K}\left(\Delta G_{800}\right)$ for the initial adsorption of $\mathrm{TiCl}_{4}$ : (a) on $-\mathrm{OH}$ functionalized Si surface; and (b) on $-\mathrm{NH}_{2}$ functionalized Si surface. ((1) Before adsorption; (2) molecular adsorption; (3) first transition state; (4) product complex; and (5) desorption of $\mathrm{HCl}$ )

After initial adsorption of the $\mathrm{TiX}_{4}$ precursor on the surface, successive ligand removal reaction can occur through additional bonding of $\mathrm{H}$ atoms of the surface functional groups with the other halogen ligands of the precursor. However, for each surface model employed, we encountered a new challenge in selecting the surface functional group to react with the second ligand of the precursor. For example, as shown in Figures S1 and S2 (Supplementary Materials), there were multiple possible reaction pathways for removing the second ligand of the $\mathrm{TiCl}_{4}$ precursor adsorbed onto the surface, and each reaction pathway had a significant reaction energy difference of up to $30 \mathrm{~kJ} / \mathrm{mol}$. Therefore, we realized that there could be multiple reaction pathways to remove the ligand for each surface model employed, and we classified the reaction pathways according to the adsorption sites and investigated the preferred structures from the thermodynamic and kinetic perspectives. For the example discussed above, when removing the second ligand of $\mathrm{TiCl}_{4}$ adsorbed on the-OH-terminated surface, it was divided into three reaction pathways, and the subsequent ligand removal reaction pathway proceeded consistently. In contrast to $-\mathrm{OH}$, the $-\mathrm{NH}_{2}$-terminated surface had two hydrogen atoms for each functional group, and, hence, we investigated the second and third ligand removal 
reactions by dividing them into four and three reaction pathways, respectively. With these, an optimized model of each ligand removal step was developed, as shown in Figure 4. We were unable to obtain the activation energy when the fourth ligand was removed; however, we empirically estimated that both surface models had higher activation energies because of the high endothermicity exhibited by the fourth ligand removal reaction $\left(\Delta E_{-\mathrm{OH}}=274.5 \mathrm{~kJ} / \mathrm{mol}\right.$ and $\left.\Delta E_{-\mathrm{NH}_{2}}=348 \mathrm{~kJ} / \mathrm{mol}\right)$. The quasi-planar square structures that are imposed to Ti after removal of all four ligands would affect such product to be strongly unfavored.

(a)
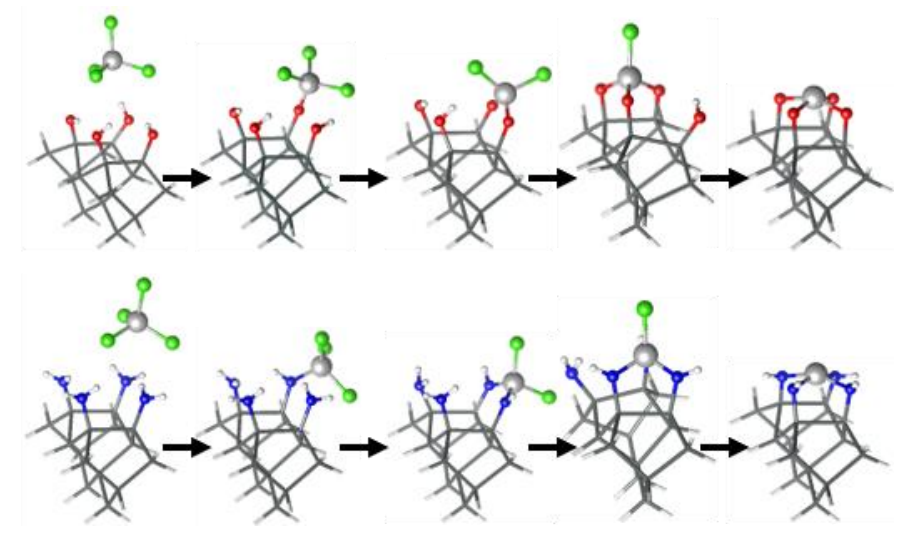

(b)

Figure 4. Considered adsorption structures for the sequential adsorption of $\mathrm{TiX}_{4}:(a)-\mathrm{OH}$ functionalized Si surface; and (b) $-\mathrm{NH}_{2}$ functionalized Si surface: (1) Molecular adsorption; (2) desorption of first HX; (3) desorption of second HX; (4) desorption of third HX; and (5) desorption of fourth HX.

According to the sequential adsorption reaction shown in Figure 4, the change in the free energy is obtained (Figure 5). A change in free energy was observed until all four hydrogen halides were removed, based on the initial adsorption energy of $0 \mathrm{~kJ} / \mathrm{mol}$. All surface models exhibited consistently high energies at each step in the order: $\mathrm{TiCl}_{4}>\mathrm{TiBr}_{4}>\mathrm{TiI}_{4}$. The reactivity between the precursor and the surface varied with the size and electronegativity of the halogen element [46]. The higher the electronegativity of the halogen element is ( $\mathrm{Cl}, \mathrm{Br}$, and I: 2.88, 2.75, and 2.6, respectively [47]), and the shorter the Ti-X bond length is $\left(\mathrm{TiCl}_{4}, \mathrm{TiBr}_{4}\right.$, and $\mathrm{TiI}_{4}: 2.18,2.34$, and $2.57 \AA$, respectively), the stronger the Ti-X bond would become [48]. The Ti-X bond dissociation energy (BDE) calculated at the current DFT level of theory are 413, 359, and $304 \mathrm{~kJ} / \mathrm{mol}$ for $\mathrm{TiCl}_{4}, \mathrm{TiBr}_{4}$, and $\mathrm{TiI}_{4}$, respectively, confirming such hypothesis. In previous studies, the relative reactivities of the compounds containing halogen ligands were compared experimentally, and a similar reactivity hierarchy was reported ( $\mathrm{I}>\mathrm{Br}>\mathrm{Cl}$ ) $[46,48]$. Our results are consistent with these findings, and the above theory suggests a comparative analysis among the different titanium halide precursors.

As shown in Figure 5, the two surface models with - $\mathrm{OH}$ and $-\mathrm{NH}_{2}$ terminations showed different energy changes during the ligand removal reaction. The adsorption mechanism on the-OH-terminated surface model is shown in Figure 5a. It is observed that, when the second ligands of the three precursors were removed, they exhibited an energy barrier of $20 \mathrm{~kJ} / \mathrm{mol}$ and an exothermicity of less than $-44 \mathrm{~kJ} / \mathrm{mol}$. We thus presume that this could be a spontaneous process. However, when the third ligand was removed, an energy barrier of $79 \mathrm{~kJ} / \mathrm{mol}$ and an endotherm of $27 \mathrm{~kJ} / \mathrm{mol}$ were obtained, and, thus, the spontaneity of the reaction could not be ascertained only from the quantity of energy. Given an endothermicity of $301 \mathrm{~kJ} / \mathrm{mol}$, the removal of the fourth ligand was expected to possess a significant energy barrier; thus, this was an unfavorable reaction step. Ghosh et al. confirmed that two chlorine ligands were released when calculating the self-limiting reaction of $\mathrm{TiCl}_{4}$ on an $-\mathrm{OH}$-functionalized $\mathrm{Si}$ surface, which is in good agreement with our obtained results [49]. 

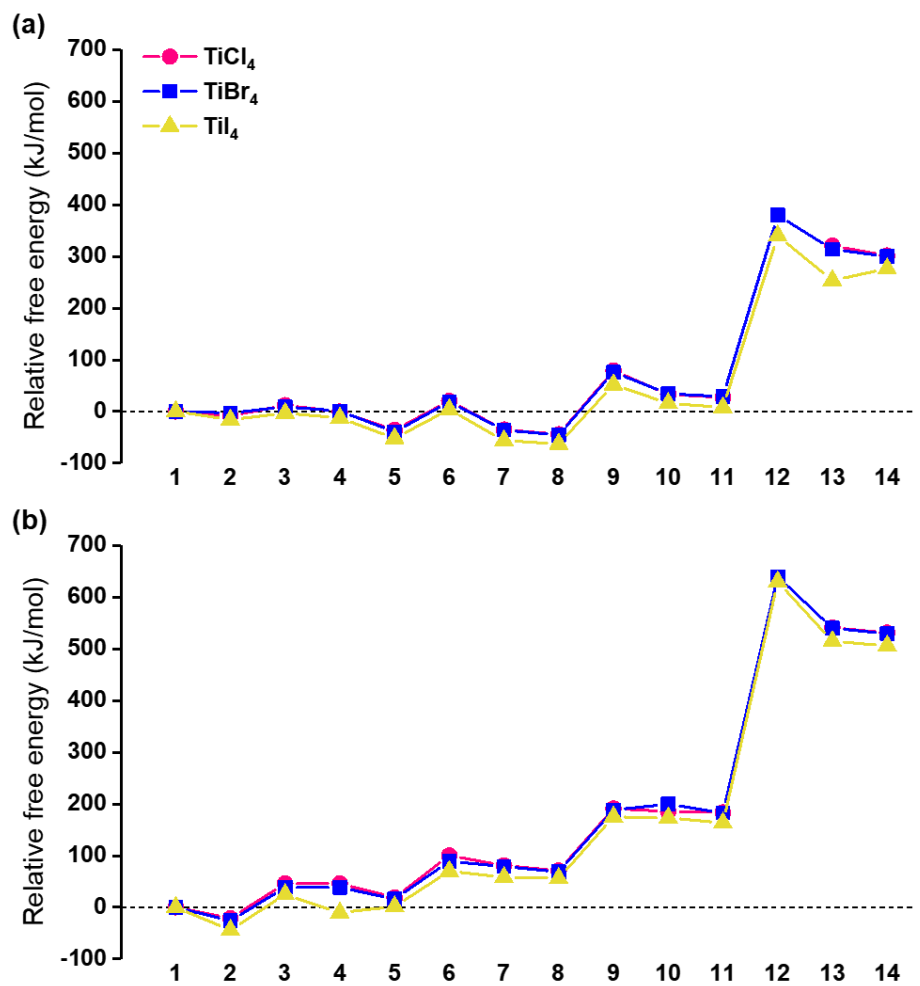

Figure 5. Gibbs free energy change for sequential adsorption of $\mathrm{TiX}_{4}$ on functionalized Si surface at room temperature: (a) $-\mathrm{OH}$ functionalized Si surface; and (b) $-\mathrm{NH}_{2}$ functionalized Si surface. (1) Before adsorption; (2) molecular adsorption; (3, 6, 9, and 12) transition states; and (4, 7, 10, and 13) $\mathrm{HCl}$-desorbed chemisorption state.

Applying such concept to the $-\mathrm{NH}_{2}$-terminated surface shown in Figure $5 \mathrm{~b}$, we obtained different results compared to those obtained for the-OH-terminated surface model. Unlike the-OH-terminated surface, when the first ligand was removed, it exhibited an energy barrier of $46 \mathrm{~kJ} / \mathrm{mol}$ and an endotherm of $19.5 \mathrm{~kJ} / \mathrm{mol}$. Although this amount of free energy was theoretically known to cause a non-spontaneous reaction, it is still difficult to determine its spontaneity, due to the relatively low endothermic value. However, when the second ligand was removed, although an energy barrier of $100 \mathrm{~kJ} / \mathrm{mol}$ and an endotherm of $71 \mathrm{~kJ} / \mathrm{mol}$ were obtained, it was still difficult to define the process as a spontaneous reaction by the energy size alone. As a result, we observed the energy change in the ligand dissociation reaction of the adsorbed precursor on the functionalized surface, and, through this, we determined the self-limiting reaction in each surface model. When the ligands of the precursor were removed by the functional groups on the surface, one or two ligands remained on the-OH-terminated surface and three or four ligands remained on the $-\mathrm{NH}_{2}$-terminated surface. The subsequent dissociation reactions were, therefore, non-preferred from the aspects of thermodynamics and kinetics.

To confirm the deposition rate of titanium-halide precursors on the-OH-terminated surface and the $-\mathrm{NH}_{2}$-functionalized $\mathrm{Si}(001)$ surface under different temperatures, we employed the transition state theory to calculate the reaction rate constant, $k$. As shown in Figure $6, k$ values on the-OH-functionalized $\mathrm{Si}$ surface were consistently higher than those on the $-\mathrm{NH}_{2}$ surface at all temperatures. This means that the $-\mathrm{NH}_{2}$ functionalized Si surface may show more significant nucleation delay than $-\mathrm{OH}$ surface, if there exists any. On the other hand, $k$ of each titanium halide precursors was on the order of: $\mathrm{TiI}_{4} \sim \mathrm{TiBr}_{4}>\mathrm{TiCl}_{4}$. Together with the thermodynamic analysis, $\mathrm{TiI}_{4}$ appears to provide the highest reactivity among the halide precursors. 


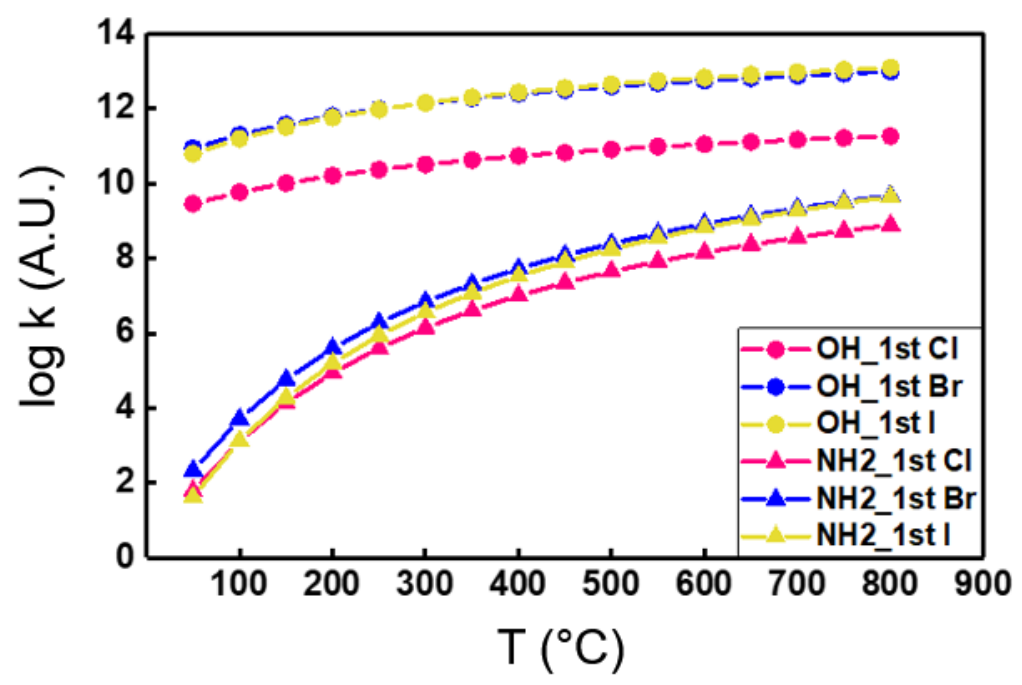

Figure 6. The reaction rate constants for Ti halide precursors first ligand dissociation on $-\mathrm{OH}, \mathrm{NH}_{2}$ functionalized Si surfaces at different temperatures.

\section{Conclusions}

In this study, we performed quantum chemical simulations to investigate the chemical phenomena that may occur during the initial film formation of $\mathrm{TiO}_{2}$ and $\mathrm{TiN}$ in ALD half-reactions. To achieve this, we modeled $\mathrm{Si}(001)$ clusters comprising four $-\mathrm{OH}$ and $-\mathrm{NH}_{2}$ functional groups, and selected $\mathrm{TiCl}_{4}, \mathrm{TiBr}_{4}$, and $\mathrm{TiI}_{4}$ precursors. Based on the reactions between the ligands of the precursors and the hydrogen atoms of the surface functional groups in the precursor-surface reaction, the hydrogen halides were removed and the reaction energies until the complete removal of the HX byproducts $(\mathrm{HCl}, \mathrm{HBr}$, and $\mathrm{HI})$ were analyzed. Then, it was confirmed that several reaction pathways exist for the removal of each ligand, and, thus, the path exhibiting the lowest reaction energy was designated as the preferred adsorption mechanism. In our results, the reaction on the-OH-terminated surface generally exhibited lower energy than those on the $-\mathrm{NH}_{2}$ surface and thus a better reactivity. This suggests that reactivity can be selectively varied depending on the functional groups, even on the same Si substrate. In addition, each surface reaction exhibited high reactivity in the order of: $\mathrm{TiI}_{4}>\mathrm{TiBr}_{4}>\mathrm{TiCl}_{4}$. Two or three ligand dissociation reactions were expected to occur on the -OH-terminated surfaces, whereas, in the case of $-\mathrm{NH}_{2}$, one or two were expected. Finally, we confirmed the selectivity of the reaction according to the surface functional groups and determined the self-limiting reaction by increasing the reaction energy as the ligands were removed. This study may find applications in comparing the difference between the adsorption behaviors, which can vary according to the precursors and surface functional groups during the ALD process.

Supplementary Materials: The following are available online at http://www.mdpi.com/2079-6412/10/8/712/s1, Figure S1: Multiple pathways of $\mathrm{TiX}_{4}$ adsorption on the $-\mathrm{OH}$ terminated Si surface, Figure S2: Multiple pathways of $\mathrm{TiX}_{4}$ adsorption on the $-\mathrm{NH}_{2}$ terminated $\mathrm{Si}$ surface.

Author Contributions: Conceptualization, B.S.; Methodology, J.P., N.K.Y., and B.S.; Software, J.P., and N.K.Y.; Validation, J.P., and B.S.; Formal Analysis, J.P., N.K.Y., and B.S.; Investigation, J.P.; Resources, D.J., E.J., H.N., J.M., D.K., and B.S.; Data Curation, J.P., and B.S.; Writing-Original Draft Preparation, J.P.; Writing-Review \& Editing, J.P., N.K.Y., and B.S.; Visualization, J.P.; Supervision, B.S.; Project Administration, D.J., E.J., H.N., J.M., D.K., and B.S.; Funding Acquisition, B.S. All authors have read and agree to the published version of the manuscript.

Funding: This work is result of a research project supported by SK hynix Inc.

Conflicts of Interest: The authors declare no conflict of interest. 


\section{References}

1. Wang, Y.; Han, R.; Liu, X.; Kang, J. The challenges for physical limitations in Si microelectronics. In Proceedings of the 1998 5th International Conference on Solid-State and Integrated Circuit Technology, Proceedings (Cat. No.98EX105), Beijing, China, 23 October 1998; pp. 25-30. [CrossRef]

2. Westlinder, J.; Schram, T.; Pantisano, L.; Cartier, E.; Kerber, A.; Lujan, G.S.; Olsson, J.; Groeseneken, G. On the thermal stability of atomic layer deposited TiN as gate electrode in MOS devices. IEEE Electron Device Lett. 2003, 24, 550-552. [CrossRef]

3. Sinke, W.; Frijlink, G.P.A.; Saris, F.W. Oxygen in titanium nitride diffusion barriers. Appl. Phys. Lett. 1985, 47, 471-473. [CrossRef]

4. Grigorov, G.I.; Grigorov, K.G.; Stoyanova, M.; Vignes, J.L.; Langeron, J.P.; Denjean, P. Aluminium diffusion in titanium nitride films. Efficiency of TiN barrier layers. Appl. Phys. A 1993, 57, 195-197. [CrossRef]

5. Reyes-Coronado, D.; Rodríguez-Gattorno, G.; Espinosa-Pesqueira, M.E.; Cab, C.; de Coss, R.; Oskam, G. Phase-pure $\mathrm{TiO}_{2}$ nanoparticles: Anatase, brookite and rutile. Nanotechnology 2008, 19, 145605. [CrossRef] [PubMed]

6. Seok, T.J.; Liu, Y.; Jung, H.J.; Kim, S.B.; Kim, D.H.; Kim, S.M.; Jang, J.H.; Cho, D.-Y.; Lee, S.W.; Park, T.J. Field-effect device using quasi-two-dimensional electron gas in mass-producible atomic-layer-deposited $\mathrm{Al}_{2} \mathrm{O}_{3} / \mathrm{TiO}_{2}$ ultrathin (<10 nm) film heterostructures. ACS Nano 2018, 12, 10403-10409. [CrossRef]

7. Kim, I.; Kumta, P.N. Hydrazide sol-gel synthesis of nanostructured titanium nitride: Precursor chemistry and phase evolution. J. Mater. Chem. 2003, 13, 2028-2035. [CrossRef]

8. Liang, Y.; Sun, S.; Deng, T.; Ding, H.; Chen, W.; Chen, Y. The Preparation of $\mathrm{TiO}_{2}$ Film by the sol-gel method and evaluation of its self-cleaning property. Materials 2018, 11, 450. [CrossRef]

9. Wang, X.-P.; Yu, Y.; Hu, X.-F.; Gao, L. Hydrophilicity of $\mathrm{TiO}_{2}$ films prepared by liquid phase deposition. Thin Solid Films 2000, 371, 148-152. [CrossRef]

10. Su, J.; Boichot, R.; Blanquet, E.; Mercier, F.; Pons, M. Chemical vapor deposition of titanium nitride thin films: Kinetics and experiments. CrystEngComm 2019, 21, 3974-3981. [CrossRef]

11. Jagadeesan, S.; Doh, Y.H.; Choi, K.-H. Low-temperature fabrication of $\mathrm{TiO}_{2}$ film on flexible substrate by atmospheric roll-to-roll CVD. J. Coat. Technol. Res. 2017, 14, 701-708. [CrossRef]

12. Singh, J.; Khan, S.A.; Shah, J.; Kotnala, R.K.; Mohapatra, S. Nanostructured $\mathrm{TiO}_{2}$ thin films prepared by RF magnetron sputtering for photocatalytic applications. Appl. Surf. Sci. 2017, 422, 953-961. [CrossRef]

13. Knoops, H.C.M.; Potts, S.E.; Bol, A.A.; Kessels, W.M.M. Atomic layer deposition. In Handbook of Crystal Growth; Elsevier: Amsterdam, The Netherlands, 2015; pp. 1101-1134. [CrossRef]

14. Chaukulkar, R.P.; Agarwal, S. Atomic layer deposition of titanium dioxide using titanium tetrachloride and titanium tetraisopropoxide as precursors. J. Vac. Sci. Technol. A 2013, 31, 031509. [CrossRef]

15. Xie, S.; Cai, J.; Wang, Q.; Wang, L.; Liu, Z. Properties and morphology of TiN films deposited by atomic layer deposition. Tsinghua Sci. Technol. 2014, 19, 144-149. [CrossRef]

16. Bronneberg, A.C.; Höhn, C.; van de Krol, R. Probing the interfacial chemistry of ultrathin ALD-grown $\mathrm{TiO}_{2}$ films: An in-line XPS study. J. Phys. Chem. C 2017, 121, 5531-5538. [CrossRef]

17. Pore, V.; Rahtu, A.; Leskelä, M.; Ritala, M.; Sajavaara, T.; Keinonen, J. Atomic layer deposition of photocatalytic $\mathrm{TiO}_{2}$ thin films from titanium tetramethoxide and water. Chem. Vap. Depos. 2004, 10, 143-148. [CrossRef]

18. Zhuiykov, S.; Akbari, M.K.; Hai, Z.; Xue, C.; Xu, H.; Hyde, L. Data set for fabrication of conformal two-dimensional $\mathrm{TiO}_{2}$ by atomic layer deposition using tetrakis (dimethylamino) titanium (TDMAT) and $\mathrm{H}_{2} \mathrm{O}$ precursors. Data Brief 2017, 13, 401-407. [CrossRef]

19. Lee, C.-S.; Kim, J.; Son, J.Y.; Choi, W.; Kim, H. Photocatalytic functional coatings of $\mathrm{TiO}_{2}$ thin films on polymer substrate by plasma enhanced atomic layer deposition. Appl. Catal. B 2009, 91, 628-633. [CrossRef]

20. Sowińska, M.; Brizzi, S.; Das, C.; Kärkkänen, I.; Schneidewind, J.; Naumann, F.; Gargouri, H.; Henkel, K.; Schmeißer, D. Analysis of nitrogen species in titanium oxynitride ALD films. Appl. Surf. Sci. 2016, 381, 42-47. [CrossRef]

21. Xie, Q.; Musschoot, J.; Deduytsche, D.; Meirhaeghe, R.L.V.; Detavernier, C.; Berghe, S.V.d.; Jiang, Y.-L.; Ru, G.-P.; Li, B.-Z.; Qu, X.-P. Growth kinetics and crystallization behavior of $\mathrm{tio}_{2}$ films prepared by plasma enhanced atomic layer deposition. J. Electrochem. Soc. 2008, 155, H688-H692. [CrossRef] 
22. Maxwell, J.L.; Black, M.R.; Chavez, C.A.; Maskaly, K.R.; Espinoza, M.; Boman, M.; Landstrom, L. Growth of normally-immiscible materials (NIMs), binary alloys, and metallic fibers by hyperbaric laser chemical vapor deposition. Appl. Phys. A 2008, 91, 507-514. [CrossRef]

23. Kim, H. Atomic layer deposition of metal and nitride thin films: Current research efforts and applications for semiconductor device processing. J. Vac. Sci. Technol. B 2003, 21, 2231. [CrossRef]

24. Wolf, S.; Breeden, M.; Kwak, I.; Park, J.H.; Kavrik, M.; Naik, M.; Alvarez, D.; Spiegelman, J.; Kummel, A.C. Low temperature thermal ALD TaN $\mathrm{N}_{X}$ and $\mathrm{TiN}_{X}$ films from anhydrous $\mathrm{N}_{2} \mathrm{H}_{4}$. Appl. Surf. Sci. 2018, 462, 1029-1035. [CrossRef]

25. Yu, I.-S.; Cheng, H.-E.; Chang, C.-C.; Lin, Y.-W.; Chen, H.-T.; Wang, Y.-C.; Yang, Z.-P. Substrate-insensitive atomic layer deposition of plasmonic titanium nitride films. Opt. Mater. Express 2017, 7, 777. [CrossRef]

26. Miikkulainen, V.; Leskelä, M.; Ritala, M.; Puurunen, R.L. Crystallinity of inorganic films grown by atomic layer deposition: Overview and general trends. J. Appl. Phys. 2013, 113, 021301. [CrossRef]

27. Moriwaki, M.; Yamada, T. Influences of Residual Chlorine in CVD-TiN Gate Electrode on the gate oxide reliability in multiple-thickness oxide technology. Jpn. J. Appl. Phys. 2001, 40, 2679-2684. [CrossRef]

28. Krylov, I.; Zoubenko, E.; Weinfeld, K.; Kauffmann, Y.; Xu, X.; Ritter, D.; Eizenberg, M. Obtaining low resistivity $(\sim 100 \mu \Omega \mathrm{cm})$ TiN films by plasma enhanced atomic layer deposition using a metalorganic precursor. J. Vac. Sci. Technol. A 2018, 36, 051505. [CrossRef]

29. Mäntymäki, M.; Hämäläinen, J.; Puukilainen, E.; Munnik, F.; Ritala, M.; Leskelä, M. Atomic layer deposition of $\mathrm{LiF}$ thin films from Lithd and $\mathrm{TiF}_{4}$ precursors. Chem. Vap. Depos. 2013, 19, 111-116. [CrossRef]

30. Mäntymäki, M.; Hämäläinen, J.; Puukilainen, E.; Sajavaara, T.; Ritala, M.; Leskelä, M. Atomic layer deposition of $\mathrm{LiF}$ thin films from Lithd, $\mathrm{Mg}(\text { thd })_{2}$, and $\mathrm{TiF}_{4}$ precursors. Chem. Mater. 2013, 25, 1656-1663. [CrossRef]

31. Raghavachari, K.; Halls, M.D. Quantum chemical studies of semiconductor surface chemistry using cluster models. Mol. Phys. 2004, 102, 381-393. [CrossRef]

32. Frisch, M.; Trucks, G.; Schlegel, H.; Scuseria, G.; Robb, M.; Cheeseman, J.; Scalmani, G.; Barone, V.; Petersson, G.; Nakatsuji, H.; et al. Gaussian 16. Gaussian Inc.: Wallingford, CT, USA, 2016.

33. Grimme, S.; Ehrlich, S.; Goerigk, L. Effect of the damping function in dispersion corrected density functional theory. J. Comput. Chem. 2011, 32, 1456-1465. [CrossRef]

34. Weigend, F.; Ahlrichs, R. Balanced basis sets of split valence, triple zeta valence and quadruple zeta valence quality for H to Rn: Design and assessment of accuracy. Phys. Chem. Chem. Phys. 2005, 7, 3297. [CrossRef] [PubMed]

35. Ochterski, J.W. Thermochemistry in Gaussian. Available online: https://gaussian.com/thermo/ (accessed on 15 July 2020).

36. Lewars, E. Computational Chemistry; Springer: Dordrecht, The Netherlands, 2003.

37. Kim, T.H.; Nandi, D.K.; Ramesh, R.; Han, S.-M.; Shong, B.; Kim, S.-H. Some insights into atomic layer deposition of $\mathrm{MoN}_{x}$ using $\mathrm{Mo}(\mathrm{CO})_{6}$ and $\mathrm{NH}_{3}$ and its diffusion barrier application. Chem. Mater. 2019, 31, 8338-8350. [CrossRef]

38. Ansari, M.Z.; Nandi, D.K.; Janicek, P.; Ansari, S.A.; Ramesh, R.; Cheon, T.; Shong, B.; Kim, S.-H. Low-temperature atomic layer deposition of highly conformal tin nitride thin films for energy storage devices. ACS Appl. Mater. Interfaces 2019, 11, 43608-43621. [CrossRef] [PubMed]

39. Rietze, C.; Titov, E.; Lindner, S.; Saalfrank, P. Thermal isomerization of azobenzenes: On the performance of Eyring transition state theory. J. Phys. Condens. Matter 2017, 29, 314002. [CrossRef]

40. Lu, H.-L.; Chen, W.; Ding, S.-J.; Xu, M.; Zhang, D.W.; Wang, L.-K. Quantum chemical study of the initial surface reactions in atomic layer deposition of $\mathrm{TiN}$ on the $\mathrm{SiO}_{2}$ surface. J. Phys. Condens. Matter 2006, 18, 5937-5944. [CrossRef]

41. Haran, M.; Engstrom, J.R.; Clancy, P. Ab initio calculations of the reaction mechanisms for metal-nitride deposition from organo-metallic precursors onto functionalized self-assembled monolayers. J. Am. Chem. Soc. 2006, 128, 836-847. [CrossRef]

42. Killampalli, A.S.; Ma, P.F.; Engstrom, J.R. The reaction of tetrakis(dimethylamido)titanium with self-assembled alkyltrichlorosilane monolayers possessing $-\mathrm{OH},-\mathrm{NH}_{2}$, and $-\mathrm{CH}_{3}$ terminal groups. J. Am. Chem. Soc. 2005, 127, 6300-6310. [CrossRef]

43. Heil, S.B.S.; Langereis, E.; Roozeboom, F.; van de Sanden, M.C.M.; Kessels, W.M.M. Low-temperature deposition of TiN by plasma-assisted atomic layer deposition. J. Electrochem. Soc. 2006, 153, G956. [CrossRef] 
44. Strobel, A.; Schnabel, H.-D.; Reinhold, U.; Rauer, S.; Neidhardt, A. Room temperature plasma enhanced atomic layer deposition for $\mathrm{TiO}_{2}$ and $\mathrm{WO}_{3}$ films. J. Vac. Sci. Technol. A 2016, 34, 01A118. [CrossRef]

45. Afshar, A.; Cadien, K.C. Growth mechanism of atomic layer deposition of zinc oxide: A density functional theory approach. Appl. Phys. Lett. 2013, 103, 251906. [CrossRef]

46. Silva, T.C.; dos S. Pires, M.; de Castro, A.A.; Lacerda, L.C.T.; Rocha, M.V.J.; Ramalho, T.C. Structure and bonding in $\mathrm{NbX}_{5} \mathrm{X}=(\mathrm{F}, \mathrm{Cl}, \mathrm{Br}$ and $\mathrm{I})$ complexes: A molecular orbital perspective in the $\mathrm{C}-\mathrm{H}$ bond activation. Theor. Chem. Acc. 2018, 137, 146. [CrossRef]

47. Boeyens, J.C.A. The periodic electronegativity table. Z. Naturforsch. B 2008, 63, 199-209. [CrossRef]

48. Chen, C.-H.; Su, M.-D. The Mechanism of $\mathrm{C}-\mathrm{X}\left(\mathrm{X}=\mathrm{F}, \mathrm{Cl}, \mathrm{Br}\right.$, and I) bond activation in $\mathrm{CX}_{4}$ by a stabilized dialkylsilylene. Chem. -Eur. J. 2007, 13, 6932-6941. [CrossRef] [PubMed]

49. Ghosh, M.K.; Choi, C.H. Initial adsorption mechanisms of $\mathrm{TiCl}_{4}$ on $\mathrm{OH} / \mathrm{Si}(100)-2 \times 1$. Chem. Phys. Lett. 2008, 457, 69-73. [CrossRef]

(C) 2020 by the authors. Licensee MDPI, Basel, Switzerland. This article is an open access article distributed under the terms and conditions of the Creative Commons Attribution (CC BY) license (http://creativecommons.org/licenses/by/4.0/). 